\title{
Aplicando Arquiteturas Pedagógicas em Objetos Digitais Interativos
}

\author{
Crediné Silva de Menezes ${ }^{1,2}$ \\ Cláudio Ferretti ${ }^{1}$ \\ Edson Luiz Lindner ${ }^{1,3}$ \\ Antonio Fonseca de Lira ${ }^{1,4}$ \\ ${ }^{1}$ Programa de Pós-Graduação em Informática na Educação - PGIE/UFRGS \\ ${ }^{2}$ Departamento de Informática - UFES \\ ${ }^{3}$ Colégio de Aplicação - UFRGS \\ ${ }^{4}$ CEFET/AM - Bolsista - FAPEAM \\ \{credine, clafer300, edson.lindner, aflira\}@ gmail.com
}

Resumo: As Arquiteturas Pedagógicas aplicadas aos objetos digitais interativos, devem permitir o desenvolvimento dos conceitos e estruturas cognitivas, tendo como idéia central a natureza do objeto e as características iniciais do problema. A concepção dessa arquitetura pode se realizar por meio de tutorias, presenciais ou virtuais, enquanto propiciam a construção cooperativa de conceitos. Neste artigo apresentamos dois exemplos de Arquiteturas Pedagógicas. Um em grupo e outro individual, ambos aplicados em estudantes de escolas públicas.

Palavras chaves: aprendizagem, arquitetura pedagógica, objetos de aprendizagem, educação a distância.

Abstract: Pedagogical Architectures applied interactive digital objects, must allow the development of the concepts and cognitive structures. The central idea of this architecture is the nature of the object and the initial characteristics of the problem. The conception of this architecture can be fulfilled through a tutor, actual or virtual, while they can propitiate the cooperative construction of concepts. In this article we present two examples of Pedagogical Architectures. One in group and another individually, both applied in publics schools students.

Key words: learning, pedagogical architectures, interactive digital objects, distance learning 


\section{Introdução}

Ao longo da história, professores vêm buscando alternativas para apoiar a aprendizagem. Nesta busca, o computador e a Internet se constituem excelentes instrumentos. Em Carvalho, Nevado e Menezes (2005) foi proposto o conceito de Arquitetura Pedagógica (AP) para explorar a inserção das tecnologias na educação. Os autores denominam de Arquitetura Pedagógica uma combinação de estratégias, dinâmicas de grupo, softwares educacionais e ferramentas de apoio à cooperação, voltadas para o favorecimento da aprendizagem. Essas arquiteturas, independente de sua natureza, usando ou não a tecnologia digital, irão sempre requerer a utilização de objetos de aprendizagem. A concepção adequada desses objetos tem implicações diretas na construção do conhecimento pelos estudantes.

De modo geral, o acesso às propriedades dos objetos é restrito aos mecanismos perceptivos. Tal percepção depende, além de fatores sensoriais, espaciais e temporais, dos sistemas de significação trazidos pelos indivíduos. Por esta razão, a realidade não pode ser apreendida em todas as suas dimensões. Disponibilizar recursos que facilitem tais processos e os coloquem dentro de um contexto cognitivo permitirá, ao ambiente digital, a adição de novos possíveis lógicos. Para facilitar esses processos pode-se conceber sessões de aprendizagem, sustentadas por arquiteturas pedagógicas apropriadas (Carvalho et al, 2005).

Os objetos de estudo e as situações com as quais lidamos todos os dias são fontes de conhecimentos e construção de conceitos. Entretanto, é possível que os sistemas de significação do sujeito não sejam suficientes para investigar suas qualidades. Essa inadequação, entre as hipóteses e as formas como os objetos e situações momentâneas respondem ao sujeito, pode criar situações perturbadoras, provocando o desequilíbrio na estrutura cognitiva (sistemas de significação) do sujeito. Ao contrário do que possa parecer, quanto mais complexo o ambiente, no sentido de disponibilizar uma maior interação, maior será a possibilidade de aprendizagem, uma vez que a qualificação de uma ação, perturbadora ou não, parte do sujeito e não dos objetos. Um objeto digital que possa atender as necessidades pedagógicas, mais que motivador, deve servir como instrumento de investigação do grau de desenvolvimento cognitivo em que se encontra o sujeito. Quando necessário, deve ter a flexibilidade de reconstruir-se, alterando sua forma e conteúdo e reestruturando-se em duas direções: variando os possíveis lógicos, enriquecendo-o com novos elementos ou alterando sua arquitetura pedagógica. Entendem-se aqui os possíveis lógicos como as diversas circunstâncias reais ou hipotéticas que derivem de uma situação concreta de forma possível ou necessária.

A observação direta do mundo real parece ser o mais adequado para a aprendizagem, por colocar-nos em contato direto como os fenômenos. Porém, algumas vezes, isto não será possível pela dificuldade de repetição dos fenômenos, pelos custos associados ou pelos riscos que podem representar a seus observadores e/ou observados. Nessas situações, pode-se ter, como alternativa, softwares que nos permite exercitar o pensamento analítico e compreender sistemas específicos. Em geral, o mundo real é estudado através de recortes denominados de micromundos.

Apesar de existirem várias maneiras de se ter este apoio computacional, esse artigo discute e exemplifica as contribuições da tecnologia digital para construção desses objetos. Nessa contribuição considera-se o uso de arquiteturas pedagógicas para obter melhores resultados de aprendizagem no uso de objetos de digitais interativos. Entre as possibilidades de processo pode-se partir de arquiteturas para a produção de um objeto 
adequado ou partir de um objeto existente e modificá-lo para adequar à arquitetura planejada. Pode-se ainda, conceber uma nova arquitetura para explorar as características de um objeto já existente.

Neste artigo apresentamos dois exemplos de arquiteturas pedagógicas. Uma delas é voltada para o trabalho em grupo, realizado em sala da aula e outra, para sessões individuais, aplicando-se o Método Clínico Piagetiano (Carraher, 1994, p. 13).

\section{Arquitetura 1 - Compreensão Coletiva de Micromundos.}

Dentro desta perspectiva, tem-se explorado o desenvolvimento de habilidades para compreensão de sistemas, por meio da utilização de mundos virtuais. Em nossas experiências temos nos preocupado com as bases da formação de conceitos para que, a partir desse referencial, possamos elaborar um ambiente de fácil compreensão, não pela simplificação de conteúdos, mas pela adequação aos sistemas naturais do pensamento humano. Por essa razão, duas abordagens são exploradas. Uma delas é partir de objetos materiais e verificar quais os processos cognitivos que estão em desenvolvimento e em qual extensão podem ser reproduzidos em formato digital. Outra é utilizar um ambiente de programação para criar um mundo virtual (micromundos), com possíveis lógicos inexistentes no mundo real, e pedir ao sujeito que o descreva. De certa forma, pode-se comparar nossa arquitetura com o trabalho de uma equipe de cientistas, buscando a compreensão de um determinado fenômeno. Nestas sessões, independente da ordem escolhida, pode-se realizar as seguintes atividades: observação/intervenção; compartilhamento de observações; síntese-formalização preliminar; compartilhamento das sínteses e formalizações; revisão das formalizações.

\subsection{Descrição da arquitetura}

Propõe-se, então, uma sessão baseada nos seguintes passos:

1. Professor apresenta aos estudantes um micromundo construído em Klik and Play;

2. Estudantes observam o mundo trabalhando em duplas, constroem modelos, discutem, comparam e revisam;

3. Estudantes constroem representações do mundo usando klik and play;

4. Estudantes comparam seus mundos, discutem e revisam;

5. Estudantes comparam o "código" do micromundo apresentado pelo professor;

6. Estudantes escrevem suas reflexões sobre o micromundo;

7. Estudantes escrevem suas reflexões sobre o processo de aprendizagem e sobre o sistema de formalização e sobre o ambiente de programação.

As propriedades do micromundo encontram-se limitadas pelas operações que o programa Klik \& Play permite realizar. Por esta razão, este mundo é finito em possibilidades de exploração pela finalidade - aprender as propriedades do software - e pelas restrições que o criador impôs ao micromundo.

À medida que o sujeito descobre as propriedades desse micromundo passa a descrevê-lo em linguagem natural, caracterizando suas percepções a partir do seu sistema de significação. A partir do momento que passa a compartilhar suas representações, por elaboração das percepções em um contexto de significação, amplia o seu conhecimento do micromundo. Inicia-se um processo de imitação, através de uma reprodução do modelo. Porém, é impossível qualquer tipo de imitação sem um domínio das ferramentas postas à disposição do indivíduo. Surge nesse momento à necessidade de compreender o formalismo, próprio da linguagem utilizada no Klik \& Play. 
O formalismo empregado em nosso trabalho perde o seu papel puramente estrutural e passa a desempenhar o de sistema assimilador, permitindo ao indivíduo acomodar as características encontradas no micromundo. Pode-se ainda pensar que, o convite para criar um novo jogo baseado no formalismo do Klik \& Play, exige do indivíduo tomadas de consciência dos processos em construção à medida que antecipa o processo como um todo e aplica-o em uma situação totalmente diversa da anterior. Esta formalização pode ser considerada como um paradigma, no sentido que impõe uma forma de ver ao micromundo.

O objetivo principal do experimento, com a $\mathrm{AP}$, não se concentra na compreensão de um trecho particular do real e sim em um mundo artificial, mostrando aos estudantes a necessidade da prática de coletivização dos conhecimentos em virtude da dificuldade que cada indivíduo tem de perceber o mundo em sua totalidade. Por outro lado, é importante mostrar a diferenciação entre as dificuldades provenientes das atuais tecnologias de informação e comunicação necessárias aos objetos de aprendizagem, assim como o planejamento pedagógico que sustentará a prática didática dos mesmos. Dessa forma, planejou-se um objeto desconhecido dos usuários, formando um micromundo a ser explorado.

Esse micromundo apresenta as seguintes propriedades:

a) objetos que apesar de parecidos com os membros de uma mesma classe, possuem comportamentos ligeiramente diferentes;

b) objetos cujo comportamento varia com o tempo;

c) objetos cuja visibilidade varie ao longo do tempo (aparece/desaparece);

d) objetos invisíveis que influenciam no comportamento de objetos visíveis;

e) objetos cujo movimento pode ser alterado por intervenção do observador;

f) permitir que o observador atue sobre objetos (por exemplo, partir em dois);

g) permitir interações indiretas, ou seja, o observador atua sobre botões que ativam/desativam propriedades dos objetos.

A Figura 1 mostra o "Editor de Níveis" do Klik \& Play com os objetos criados. 


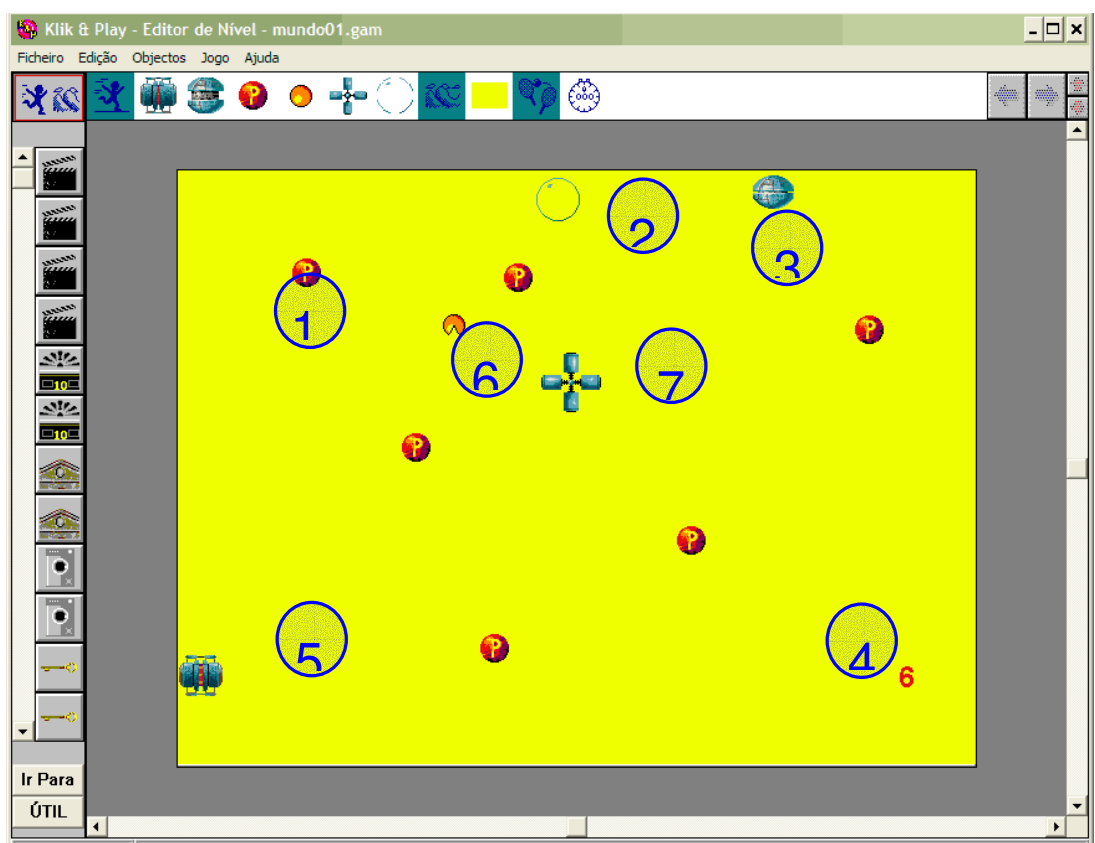

Figura 1: Tela do editor de níveis do Klik\&Play do objeto micromundo

Cada elemento dentro deste micromundo desempenha um papel específico apresentado na Tabela 1.

Tabela 1: Propriedade e interações dos objetos presente no micromundo digital.

\begin{tabular}{|c|c|c|}
\hline & Objeto & Propriedades e Interações \\
\hline 1 & Esfera "P" & $\begin{array}{l}\text { O objeto movimenta-se em todas as direções, com início } \\
\text { aleatório, mudando de direção ao chocar-se com o objeto } 5 \text { e } \\
\text { paredes. É destruído pelo choque com os objetos } 6 \text { e } 7 \text {, cria uma } \\
\text { outra esfera "P" pelo choque com o objeto } 5 \text {, que surge no } \\
\text { objeto } 2 \text { (Fonte). }\end{array}$ \\
\hline 2 & Fonte & $\begin{array}{l}\text { Neste local surgem os objetos } 1 \text { gerados pelos choques com o } \\
\text { objeto } 5 \text {. }\end{array}$ \\
\hline 3 & $\begin{array}{l}\text { "Bolacha" } \\
\text { Vertical }\end{array}$ & $\begin{array}{l}\text { Esse objeto movimenta-se na vertical, indo de um extremo a } \\
\text { outro da área de trabalho; rebate apenas no objeto } 6 \text {. }\end{array}$ \\
\hline 4 & Contador & Indica o número de objetos 1 presentes na área trabalho. \\
\hline 5 & $\begin{array}{l}\text { "Tonel Rolante" } \\
\text { Horizontal }\end{array}$ & $\begin{array}{l}\text { O objeto movimenta-se na horizontal. Em um primeiro } \\
\text { momento rebate no objeto } 3 \text { e retorna. Caso haja um choque } \\
\text { com o objeto } 7 \text {, sofrerá alteração no percurso, podendo ir de um } \\
\text { extremo a outro da área ativa; rebate com os objetos, exceto com } \\
\text { o objeto } 6 \text {. }\end{array}$ \\
\hline 6 & $\begin{array}{l}\text { Destruidor } \\
\text { "Pacman" }\end{array}$ & $\begin{array}{l}\text { Movimenta-se em todas as direções, rebate apenas nas } \\
\text { paredes e destrói o objeto } 1 \text { no choque. }\end{array}$ \\
\hline 7 & "Cruz" & $\begin{array}{l}\text { O objeto movimenta-se com o auxílio do teclado (setas } \\
\text { direcionais), destruindo o objeto } 1 \text {, ao chocar-se com ele. }\end{array}$ \\
\hline
\end{tabular}




\subsection{Aspectos cognitivos observados}

A partir do uso da Arquitetura pode-se fazer as seguintes considerações à respeito dos aspectos cognitivos observados. Um deles é o desequilíbrio cognitivo, considerado como uma perturbação no sistema de significação do indivíduo. $\mathrm{Na}$ análise do micromundo, o desequilíbrio ocorre pela necessidade da compreensão das características dos elementos presentes. Outro aspecto é o número de possíveis lógicos, representados pelas variações dos eventos, que são inseridos no micromundo. A interação entre o sujeito e o objeto de estudo é um aspecto cognitivo importante, pois permite a reequilibração cognitiva do indivíduo e a exploração dos possíveis lógicos por meio de abstrações reflexionantes. O compartilhamento dos conhecimentos adquiridos através das comparações e dos resultados da análise individual com os demais sujeitos é também um aspecto cognitivo que merece ser destacado nessa arquitetura. Durante todo o processo, o registro das ações, individuais e coletivas, permitiu as reflexões e tomadas de consciência fundamentais para a compreensão do micromundo considerado.

\section{Arquitetura -2 (utilizando o método clínico)}

Suponhamos agora que se deseje realizar uma sessão de aprendizagem para construção do conceito de equilíbrio dos corpos extensos (somatório dos momentos angulares). A Arquitetura Pedagógica, nessa sessão, tem como base acompanhar o desenvolvimento das atividades de cada aprendiz, propondo novos problemas utilizando o Método Clínico Piagetiano. Este método é uma técnica de investigação baseada na entrevista pessoal, onde as ações do sujeito podem ser registradas e posteriormente analisadas, com a finalidade de descobrir a gênese e o desenvolvimento dos seus conhecimentos.

Em AP, essa técnica pode ser adaptada, tendo como finalidade, a promoção das interações entre experimentador e sujeito, auxiliando o sujeito na construção de novos conhecimentos, a partir dos já existentes em seu sistema de significação.

Neste trabalho optou-se por tratar o estudo do equilíbrio com o uso de balanças. Para tanto, concebeu-se a balança apresentada na Figura 2, onde o centro de apoio pode ser alterado ao longo de toda a prancha, ampliando as possibilidades de verificação dos processos cognitivos em desenvolvimento durante a interação do aprendiz com o objeto.

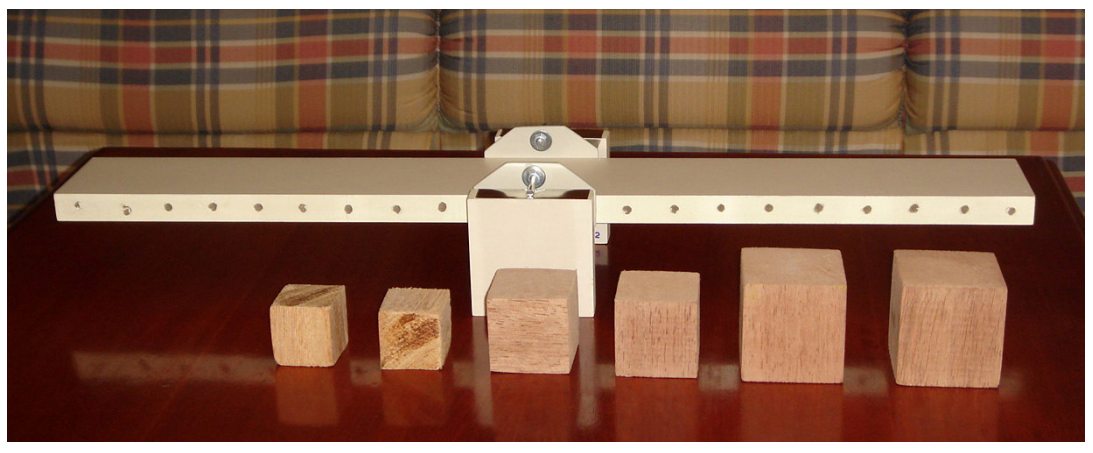

Figura 2: Balança de braços tipo gangorra

O número de possibilidades de exploração aumenta na medida em que são utilizados três tipos de balança: simétrica, assimétrica e balança sobre balança. As atividades são construídas sobre a premissa de tentar sempre desequilibrar os sistemas de significações 
do indivíduo procurando evidenciar suas certezas provisórias e dúvidas através de questionamentos baseados nas respostas do sujeito. A partir do estudo realizado com o objeto material, pôde-se conceber um objeto digital que permitisse ao sujeito desenvolver os mesmos processos cognitivos da balança material. $\mathrm{O}$ objeto digital deve ser o mais realístico possível, podendo ainda contar com um tutor à distância que interaja com o sujeito e possa oferecer-lhe desafios personalizados, de acordo com o processo cognitivo que esteja em desenvolvimento naquele momento. A aplicação de contraprovas, fator importante para verificação de certezas provisórias e tomadas de consciência, poderá ser realizada também no virtual.

Pode-se exemplificar a seqüência da seguinte forma:

a) Primeiramente, trabalha-se com a balança com os braços simétricos, onde o sujeito deve buscar o equilíbrio com um bloco, dois blocos iguais, dois blocos diferentes e com três blocos. Nessa situação busca-se identificar no sujeito a noção de compensação peso-distância.

b) Posteriormente, modifica-se a balança para que a mesma fique assimétrica buscando diferenciar os sujeitos que apresentam a noção de equilíbrio por simetria (baseado na ação) daqueles que a apresentam de forma operatória (baseado nas coordenações inferenciais).

c) Em uma terceira situação, coloca-se uma balança de menores proporções em um dos braços da balança original, verificando a capacidade do sujeito na transposição do conceito estruturado para essa nova situação.

Do ponto de vista teórico pode-se dizer que um sujeito domina tal conceito quando consegue operar com as relações de "grupos comutativos tipo INRC (Identidade, Negação, Reciprocidade e Correlatividade)”.

As relações do grupo INRC podem ser trabalhadas de varias formas, tais como: a) equilibrar dois blocos de tamanhos diferentes; b) compensar a alteração do peso, com a distância e c) reequilibrar a balança em função do tamanho diferenciado dos braços.

\subsection{Uma implementação 3D para a Balança}

A Figura 3 apresenta uma interface da implementação 3D para a balança ${ }^{1}$ concebida segundo os requisitos apresentados na subseção anterior.

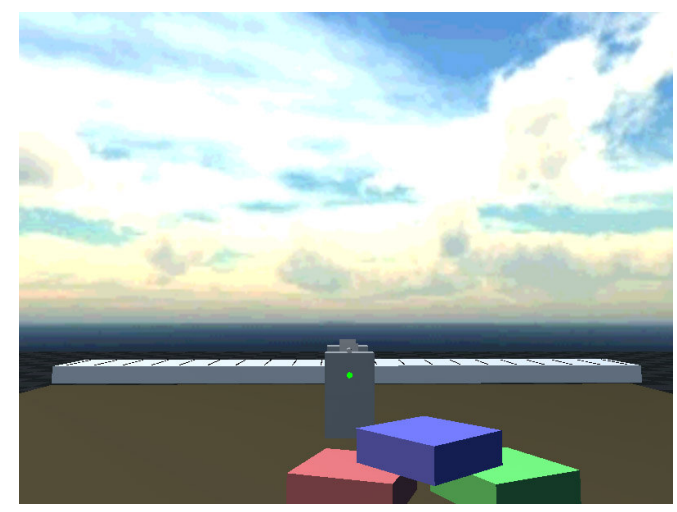

Figura 3: Simulação 3D da balança tipo gangorra

Os mesmos movimentos encontrados na balança material serão executados na simulação 3D. Para a escolha dos blocos, foi adaptado um menu flutuante apresentado 
na Figura 4, no qual se pode escolher o "tamanho" dos blocos e, clicando-se nas esferas à esquerda, a cor que se deseja dar a cada bloco. Um mostrador no apoio central da balança (podendo mudar da cor verde para a vermelha), indica a posição de equilíbrio, dentro de uma faixa de $\pm 5^{\circ}$ da horizontal, observado na Figura 5. A balança digital apresenta um coeficiente de amortecimento maior que o real, diminuindo o número de oscilação ao equilíbrio. Observou-se, na prática, que tal fator é pouco significante para o experimento, podendo ser eliminado sem alteração cognitiva.

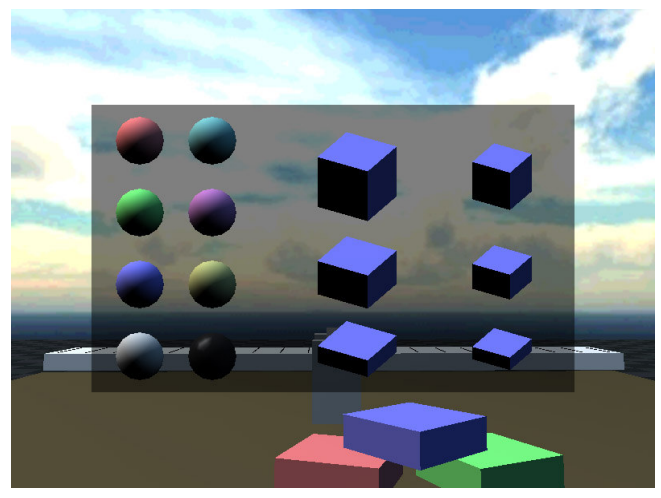

Figura 4: Apresentação do menu flutuante para a escolha de blocos

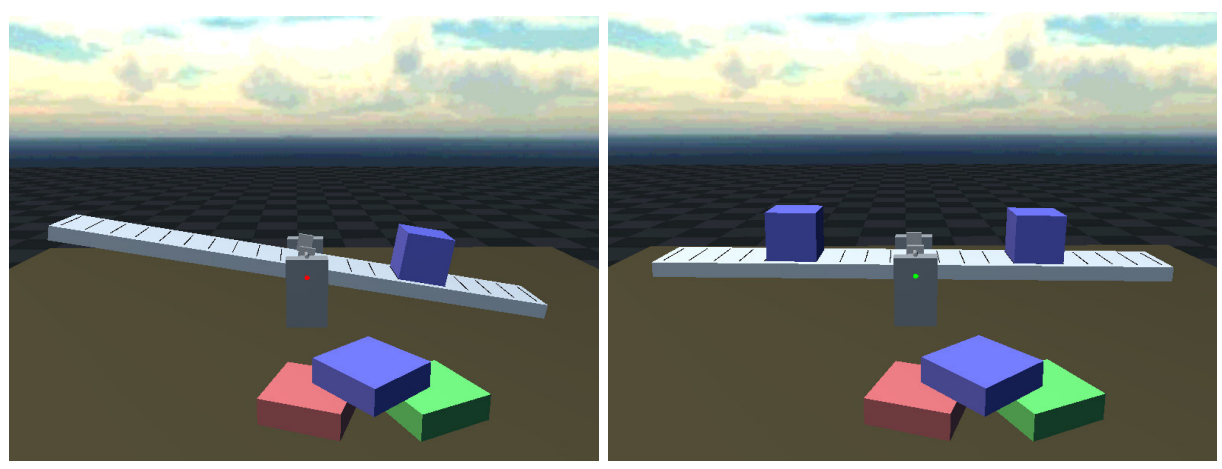

Figura 5: Mostrador central indicador de equilíbrio na balança digital.

O mesmo procedimento foi realizado para as balanças: assimétrica e dupla, apresentadas na Figura 6.
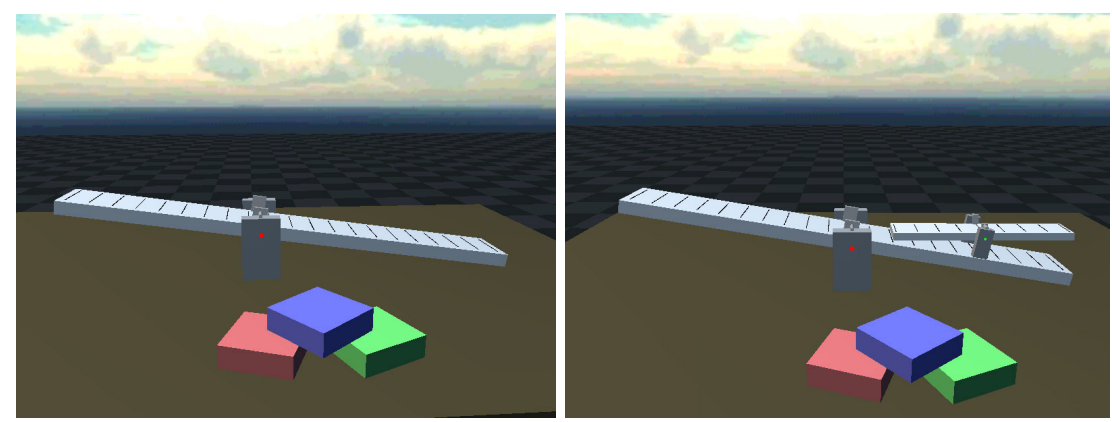

Figura 6: Balanças digitais, assimétrica e dupla.

\subsection{Considerações sobre a realização digital da balança}

De modo geral, tem-se percebido que a destreza no manuseio do mouse e das teclas de 
navegação permite ao sujeito retirar mais informações do objeto de aprendizagem. Quando em dúvida na posição de um bloco ou na inclinação da balança, estudantes mais experientes mudam o ângulo de visão ou se aproximam da prancha, facilitando sua observação.

Como o ambiente de exploração é digital, pode-se agregar ao objeto o registro de todas as operações realizadas pelo sujeito, permitindo, assim, que o professor possa conhecer todas as suas atividades, ainda que não esteja presente. A partir desses dados, o professor que domina uma teoria epistêmica terá a possibilidade de acompanhar o desenvolvimento dos processos cognitivos presentes na interação entre o sujeito e o objeto.

A natureza digital nos proporciona, ao invés de um único exemplar, toda uma classe de balanças que podem ser obtidas pela customização dos parâmetros que representem suas propriedades físicas, tais como, acabamento de superfície, cor, forma, volume e substância dos pesos, comprimento dos braços, etc. Isso permitirá agregar possíveis lógicos ao objeto digital, que implicariam, no caso dos objetos reais, a uma replicação de inúmeros objetos, o que se torna inviável economicamente para o sistema escolar.

O registro das interações de diferentes sujeitos com a balança pode ser armazenado em um banco de dados que pode alimentar um agente sintético (inteligente) que, agindo como tutor, pode propor novas questões, incluindo diferentes mídias, simulações, etc, levando, dependendo do tipo de resposta, a uma nova etapa construtiva.

\subsection{Aspectos cognitivos observados}

À semelhança do que apresentamos na seção 2.2, o uso da Arquitetura-2 nos permite fazer considerações sobre os aspectos cognitivos. Com respeito aos desequilíbrios cognitivos, pode-se afirmar que eles se manifestam de várias maneiras: a distribuição dos blocos na balança simétrica, o uso de balanças assimétricas, o uso de blocos com matérias de diferentes densidades etc. Quanto aos possíveis lógicos, pode-se citar: a mudança do ponto de apoio, as diversas posições onde os blocos podem ser localizados, o uso de braços de tamanho idêntico, mas com densidades diferentes e a proporção de massa entre os diferentes blocos. A interação entre o sujeito e o objeto ocorre quando o estudante distribui os blocos sobre os braços, ou na mudança do ponto de apoio da balança, buscando o equilíbrio físico. Aqui o registro das ações individuais, permite ao professor as reflexões e tomadas de consciência fundamentais para a compreensão do processo de aprendizagem dos seus estudantes.

\section{Considerações Finais}

As experiências realizadas sinalizam que o trabalho com a construção de objetos de aprendizagem, seguindo esta abordagem, é adequado e tem levado ao desenvolvimento de objetos mais sintonizados com as práticas construtivistas.

As reflexões sobre a natureza digital dos objetos de aprendizagem interacionistas apontam vantagens adicionais às comumente observada, tais como:

- No virtual existe a possibilidade de criar objetos de diversos níveis de interação, tal como ocorre com os videogames, onde os jogos possuem vários graus de dificuldade. Um mesmo objeto pode ser reconfigurado conforme as interações de um estudante;

- Aos objetos digitais podem ser integrados agentes inteligentes que desempenhem, de alguma forma, o papel de um assistente que poderia instigar a exploração por parte do estudante; 
- Objetos podem fazer os registros dos usos, por diferentes sujeitos, possibilitando a criação de ferramentas de apoio à análise do professor e reflexão do estudante;

$\mathrm{O}$ aspecto comum dos dois tipos de arquitetura apresentados neste artigo, aponta para a relevância de uma tutoria, ou melhor, a atuação de um tutor, quer seja humano ou sintético, como agente capaz de propor situações que levem o sujeito à construção dos conceitos e à formação das estruturas cognitivas.

Um outro aspecto pertinente à AP é a necessidade de registro dos eventos do processo. Isto permite a reflexão sobre o desenvolvimento desse processo e da atuação do sujeito. Pode-se citar, como ambiente de registro, os de construção colaborativa, como o Wiki. Além disso os registros digitais do tipo log e/ou filmagem permitem uma análise mais detida dos processos envolvidos nas sessões de aprendizagem, bem como aquelas situações onde a presença de um tutor pudesse influenciar a interação do sujeito com os objetos.

No prosseguimento desta pesquisa, pretende-se, após uma melhor validação da estratégia, conceber assistentes computacionais que auxiliem o trabalho dos professores, que, a partir dos registros digitais gerados, possam ajudar na elaboração de feedbacks apropriados.

\begin{abstract}
Notas
${ }^{1} \mathrm{O}$ objeto foi implementado em LUA (Lua, 2006), uma linguagem de programação criada no laboratório universitário da PUC-Rio em 1993 e hoje é usada mundialmente em aplicativos diversos como jogos, controles de robôs, sistemas embarcados e testes programados de equipamentos. Tal linguagem permite implementar simulações em tempo real, compatível com a tecnologia hoje existente, a partir de um servidor. No momento, já é possível registrar os movimentos do sujeito através de log, gravação de tela e voz locais.
\end{abstract}

\title{
5. Referências Bibliográficas.
}

AZEVEDO, L.L.; Menezes, C.S.; Corso, B., Pontarolo, E. Ambientes Computacionais Orientados a Agentes para apoio à Aprendizagem Baseada em Simulação. In: Simpósio Brasileiro de Informática na Educação, 2005, Juiz de Fora - MG. Anais. Juiz Fora Sociedade Brasileira de Computação.

CARRAHER, T. Nunes. O Método Clínico: Usando os Exames de Piaget. Quarta Edição. Editora Cortez. São Paulo, 1994.

CARVAlHO, M.J. S., 2005, Nevado, R.A., Menezes, C.S., Arquiteturas Pedagógicas para Educação a Distância: Concepções e Suporte Telemático. In: Simpósio Brasileiro de Informática na Educação, 2005, Juiz de Fora - MG. Workshop Arquiteturas Pedagógicas para Suporte à Educação a Distância Mediada pela Internet.

PIAGET, Jean. A Formação do Símbolo na Criança - Original: La Formation du Symbole chez L'enfant. Zahar Editores, Rio de Janeiro, 1971. 